The event of the chilota maja. Rural chichería in Manao

PALABRAS CLAVE - ACONTECIMIENTO - CHILOÉ - MAJA · MANZANAS · RURAL

KEYWORDS - EVENT · CHIIOÉ · MAIA · APPIES · RURAL

\title{
El acontecimiento de la maja chilota
}

\author{
Chichería rural en Manao
}

DANIEL SANDOVAL ALONSO · Santiago. Chile · daniel.sandoval@ug.uchile.cl

Profesor Guía: LORENZO BERG

\section{LOS ACONTECIMIENTOS}

En el conjunto rural chilote, más allá de los componentes corpóreos que lo conforman, se desarrollan una serie de acontecimientos de una vida rural en comunidad que constituyen un imaginario particular. Precisamente, aquel imaginario de habitar este territorio en la colectividad es el origen de este proceso de proyectación arquitectónica.

Los acontecimientos de la vida rural en Chiloé, son entendidos como eventos productivos que requieren una previa organización entre personas, y que signifiquen un cese de la labor cotidiana para quienes habiten el territorio, como también para quien ha tenido la oportunidad de observar y participar. Son acontecimientos que a su vez forman parte de un sistema de vida en conexión con la naturaleza. Cosechas, carneos, recolectas, y traslados son acciones estacionarias, y son permitidas desde una simple baja en la marea, un día menos lluvioso, hasta el crecimiento anual del ganado, o las temporadas de maduración agrícola. La minga surge como el concepto que engloba aquella organización social vinculada a estas actividades productivas, siendo una base cultural, con trabajo, reuniones sociales, comidas, bailes, e intercambio material, donde el dinero - aquello que mueve nuestro sistema actual - ni si quiera se asoma. Estas formas de vida colectiva son la base de la cultura chilota, y hacen sentido como respuesta ante la subsistencia en un gélido territorio como éste.

Estas actividades productivas que involucran un acontecimiento, a su vez necesitan de un soporte material, y es precisamente en ese punto donde la arquitectura cobra sentido. El imaginario corpóreo del Chiloé rural, adquiere valor debido al acontecimiento que arraiga detrás; lo construido toma sentido al ser el soporte de dichos acontecimientos. El producto y el espacio de producción necesitan al acontecimiento para su existencia, y a su vez el acontecimiento necesita de un espacio y deriva en un producto. Así, lo construido por los chilotes, se presenta de la manera más honesta posible, donde la forma es tan solo una resultante de la acción de contener un acontecimiento. 


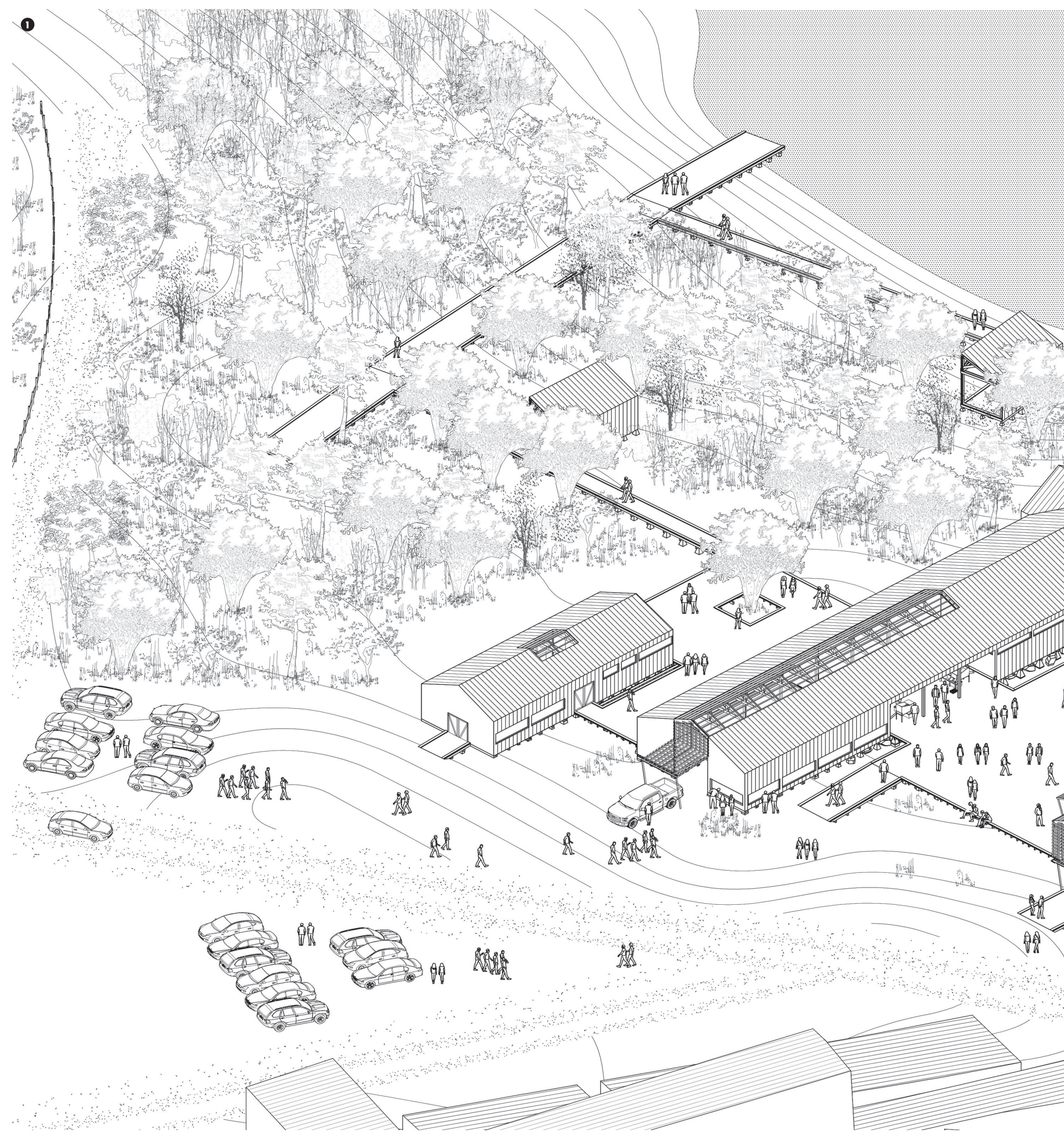




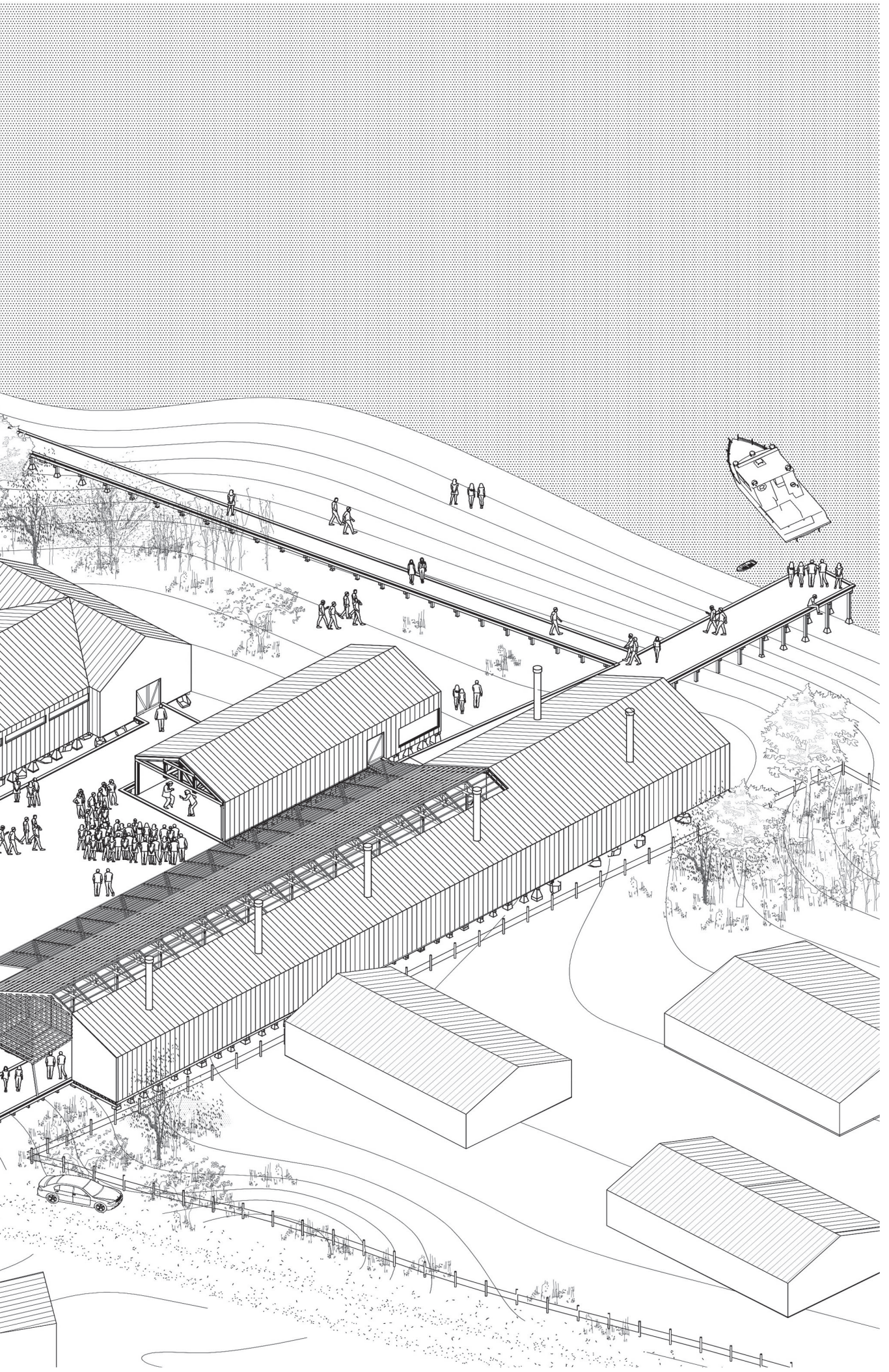

1. Isométrica. Elaboración propia. 
2. Planta. Elaboración propia.

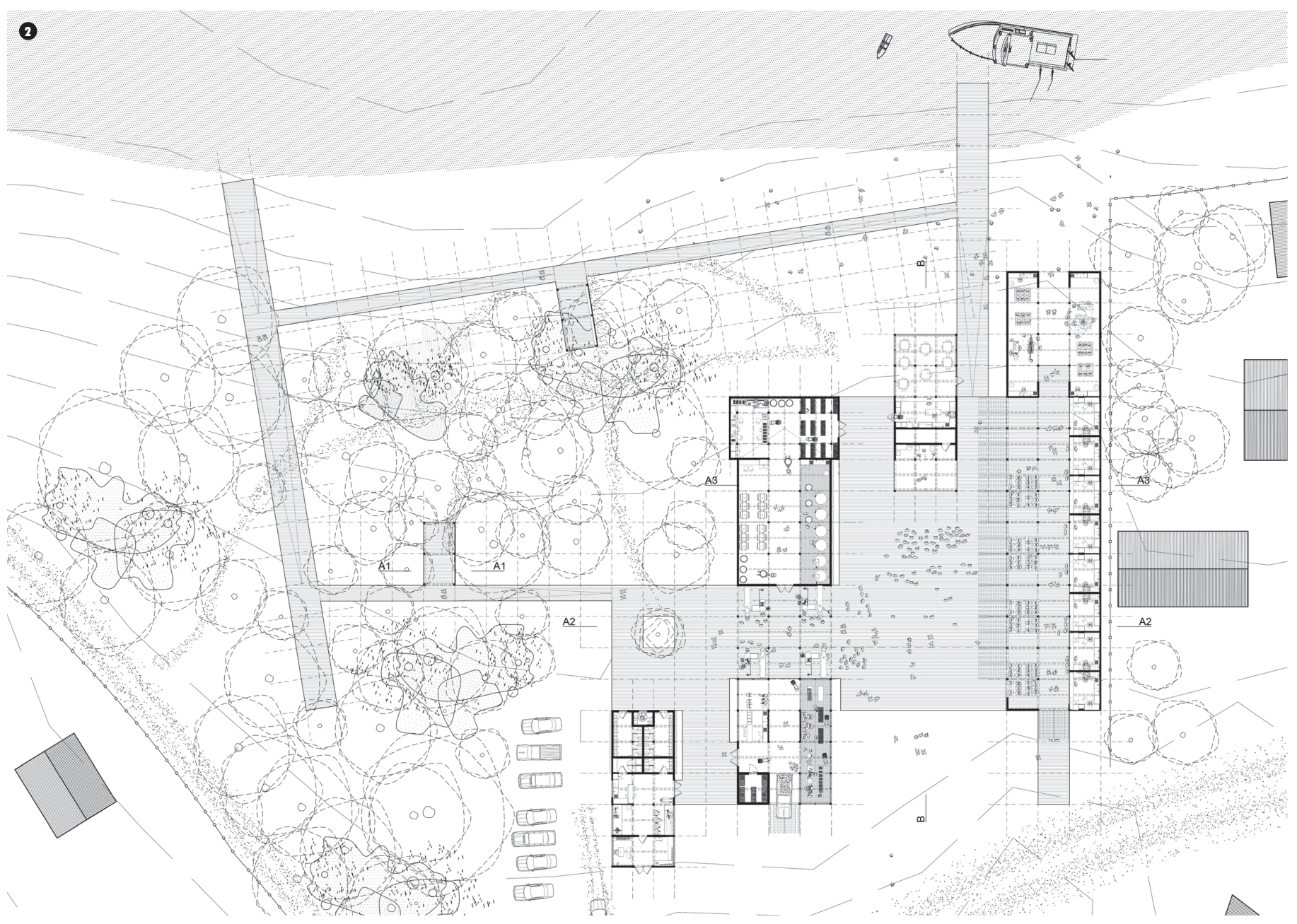




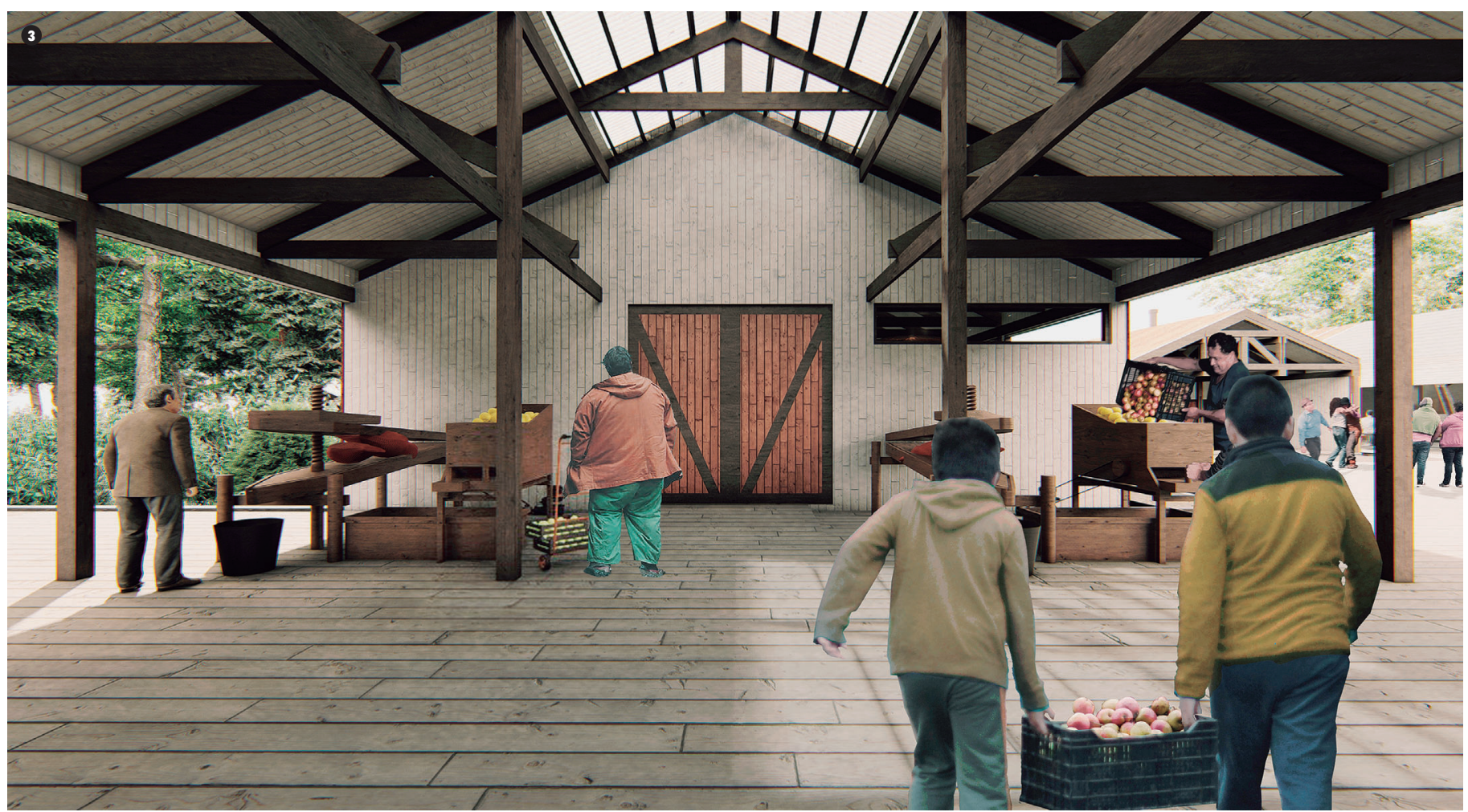

\section{EL HUERTO DE MANZANOS}

Entre estos acontecimientos, la producción de chicha de manzanas se sitúa como uno de los inmanentes de la vida rural chilota. Su origen material, el huerto de manzanos, es un fiel reflejo del sincretismo, siendo un componente esencial del conjunto rural chilote desde los tiempos coloniales. Desde su aporte paisaístico en lo espacial, hasta su aporte productivo tanto por el fruto como por la elaboración de diversos productos, el huerto de manzanos es el origen de un destacado patrimonio agrícola y gastronómico de Chiloé. Particularmente, la producción de chicha de manzanas es una actividad tradicional aún vigente en las localidades rurales, que refleja un sinnúmero de atributos; el trabajo de una tierra fértil, el conocimiento agrícola, el conocimiento en la elaboración de fermentados, la destreza carpintera en la maquinaría, el trabajo colaborativo, entre muchos otros asociados a estos.

Así, la elección de la chicha de manzanas y de su proceso productivo se vuelven sugerentes como los elementos a poner en valor en este proyecto de arquitectura, para así poder cuidar un patrimonio vivo y a la vez potenciar la vida en la ruralidad, entendiendo esto último como uno de los temas cruciales por abordar desde la arquitectura en el contexto actual.

\section{LAS CONSTRUCCIONES}

¿Objeto o espacio? ¿̇Materia o memoria? ¿Tangible o intangible? ¿̇isible o invisible? ¿̇Lo poético o lo corpóreo? ¿̇Puede el espacio ser un objeto? ¿Puede un acontecimiento ser una construcción?

Un acontecimiento y el objeto asociado a aquel acontecimiento en la vida rural de Chiloé, se posicionan como los casos de estudio. Desde su entendimiento primigenio de evento y materia como elementos disociados, hasta un entendimiento arquitectónico, donde cuya relación espacial se haga posible de proyectar, y el acontecimiento se convierta en materia sin modificar su esencia.

Pero en tal ambición de llevar un acontecimiento a ser una construcción, surge la pregunta inversa. ¿̇Puede una construcción ser un acontecimiento? 


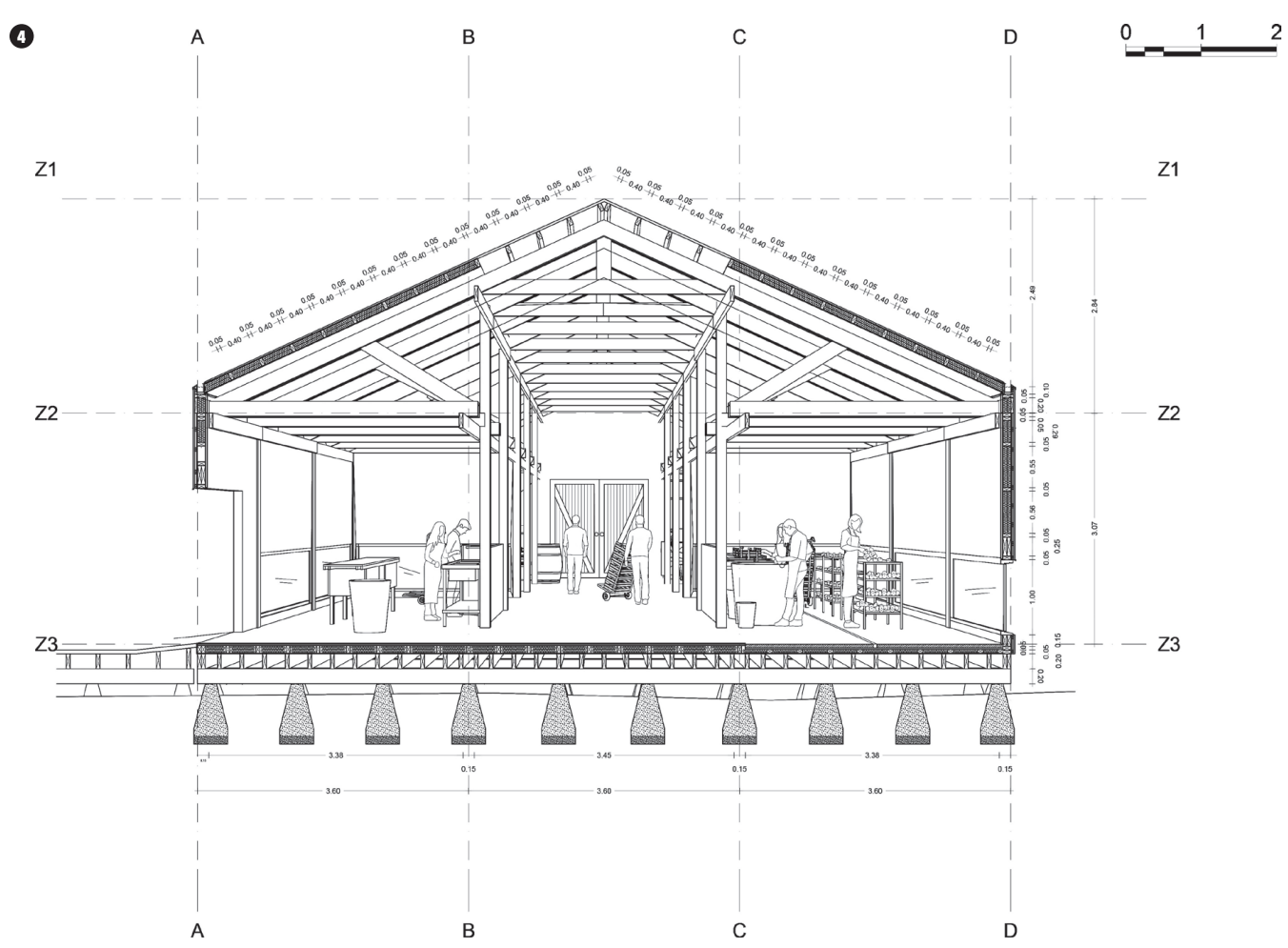

Construcciones del conjunto rural chilote son las que sin duda se han transformado momentáneamente en distintos acontecimientos. Construcciones como el molino, el galpón, una torre de agua, el invernadero, un gallinero, - la misma casa chilota que por sí solos cumplen una función particular - algunas veces imprescindibles de un habitar- pero dan la posibilidad a ser transformados en cuanto los habitantes los necesitan como soporte espacial para otros acontecimientos particulares.

Las construcciones chilotas, sus materialidades y transformaciones, se vuelven en los referentes directos del proyecto. Su simpleza y pragmatismo, más aún cuando hay preexistencias como en el caso de la ex escuela rural de Manao, se convierten en la plantilla base para la proyectación, dando como resultante un ejercicio de composición del espacio en base a galpones existentes y nuevos, que van dando grano en la multiescala de la intervención.

Acciones de posicionamientos, prolongaciones, aperturas, cierres, y conexiones, arman los elementos tipológicos como la explanada, el exterior cubierto, el interior agalponado de tres naves, y un sistema de recorridos, que convergen en un nuevo conjunto rural chilote de carácter público y productivo a la vez.

El proyecto de la chichería en Manao, se piensa así como una construcción que albergue en su interior espacios particulares para la producción de chicha de manzana en base a técnicas tradicionales, acogiendo dicho acontecimiento productivo sin perder la esencia de la forma en que los habitantes lo realizan. Una construcción que renueve el contenedor de la actividad productiva pero mantenga el acontecimiento. Una simbiosis entre nuevas espacialidades en conjunto a las locales, con criterios de habitabilidad que repercutan en la productividad, para así armar una producción de cooperativa entre vecinos, que pueda dar un sustento económico a las familias rurales en base al cuidado de su propia cultura. Un proyecto que responde ante la necesidad de habitar el mundo rural - inserto ya en el sistema país - pero de forma sostenible y cuidadosa con la cultura y el entorno. De esta forma la arquitectura toma un argumento político. La chichería se posiciona como una alternativa distinta ante las lógicas productivas industriales actuales, no solo para revalorizar el patrimonio rural que arraiga un producto particular chilote y sus técnicas de producción, sino que también como una forma de rescate ante la amenaza a desaparecer por la inminente llegada de industrias extractivas, como ya ha ocurrido con diversos productos y prácticas culturales locales. 